\title{
Regulatory niches: diagnostic reform as a process of fragmented expansion. Evidence from the UK 1990-2018
}

\author{
Stuart Hogartha (sh339@cam.ac.uk) \\ Olga Löblováa \\ ${ }^{a}$ Department of Sociology, University of Cambridge, 16 Mill Lane, Cambridge, CB2 1SB, United \\ Kingdom
}

\begin{abstract}
This paper analyses the politics of regulatory expansion within the diagnostics sector. Since 1990, an informal, clinician-led process of diagnostic innovation within the UK NHS has been challenged by new mechanisms for the evaluation of diagnostics. We describe these diagnostic reforms as a process of fragmented regulatory expansion. New governance mechanisms function as regulatory niches: discrete spaces within an overarching sociotechnical regime. The boundaries of regulatory niches are organisational and epistemological. Organisational boundaries map onto established communities of practice that constitute the regulatory target; epistemological boundaries are defined by distinctive evaluation frameworks. Niches are also distinguished by their outcomes (rate of positive decisions) and their origins. Niche formation was triggered by five drivers: public scandal; technological change; marketisation; institutional isomorphism; and transnational policy transfer. Each niche was triggered by a unique confluence of these drivers, but common to all were historic shifts in healthcare politics, as the rise of evidence-based medicine intersected with the centralising impulse of the regulatory state, which encroached on clinical autonomy in a contest for power that is increasingly mediated by influential non-governmental organisations.
\end{abstract}




\section{Keywords}

diagnostics; regulation; genomics; health technology assessment; innovation; screening; evidence-based medicine; marketisation

\section{Introduction}

In 2006 the United Kingdom's Royal College of Pathologists published a report calling for a new framework for diagnostic innovation, one that would provide a comprehensive and systematic approach to the evaluation of new tests before adoption in the National Health Service (NHS). In setting the context for its reform agenda, the Royal College described the traditional model of diagnostic test development thus:

\footnotetext{
"Historically the introduction of new tests has been a piecemeal, evolutionary process with useful new assays being gradually disseminated throughout the NHS only after a prolonged period of evaluation in different centres. They would commonly be established in university laboratories, initially used by associated NHS departments, then as a referral service by other NHS laboratories, then (if justified by demand) implemented in local NHS laboratories. Decisions would be left to the clinicians responsible for individual patients, in consultation with relevant senior laboratory staff" (Royal College of Pathologists 2006, 3).
}

The process bears the characteristic features of Hopkins' (2006) "hidden innovation system" described in his account of the development of new genetic tests within the UK NHS: a diffuse process of technological development that has no single central node, no clear distinction between research and clinical care, no clearly defined development pathway (in contrast to the well-established three-phase clinical trial process used in drug development) and a limited role for industry. In arguing that this model was no longer 
appropriate, the Royal College of Pathologists (RCPath) were aligning with the forces of "diagnostic reform", a term we use to describe the process of regulatory expansion within the diagnostics sector (for further elaboration, see Hogarth, Miller and Sturdy, this issue).

Regulation of health technologies takes many forms: statutory controls on market licensing, clinical guidelines defining appropriate use, and funding decisions by healthcare payers. Our paper focuses on the latter. The evaluation of diagnostics for coverage purposes is of eminent real-world importance: whether the NHS funds a technology determines its availability in clinical practice, and the scope of its use, i.e. the permitted clinical indications and patient populations. Technology adoption was once a question for the clinical judgement of individual physicians, but the rise of evidence-based medicine (EBM) and health technology assessment (HTA) has institutionalised formal decisionmaking and circumscribed clinical discretion.

The UK is a particularly rich case, since its healthcare system has a long tradition of coverage regulation, exemplified by the National Institute for Health and Care Excellence (NICE), an independent agency producing guidance and recommendations on drugs, medical devices, interventional procedures and clinical practice. NICE is regarded as having greater international influence than any other HTA body (Benoit and Gorry 2017).

Table 1. Number of valid guidance documents issued by NICE by technology type, before and after the creation of the DAP and MTEP in 2009/10

\begin{tabular}{|l|l|l|l|l|l|}
\hline Diagnostics & $\begin{array}{l}\text { Medical } \\
\text { devices }\end{array}$ & $\begin{array}{l}\text { Interventions } \\
\text { and other } \\
\text { technologies }\end{array}$ & & Pharmaceuticals & $\begin{array}{l}\text { Diagnostics as } \\
\% \text { of all }\end{array}$ \\
& & & & technologies \\
& & & & assessed \\
\hline
\end{tabular}




\begin{tabular}{|c|c|c|c|c|c|}
\hline $\begin{array}{l}\text { Technology Appraisal } \\
(2001-2009)\end{array}$ & $1 *$ & 8 & 14 & 72 & $1 \%$ \\
\hline $\begin{array}{l}\text { Technology Appraisal } \\
(2010-2018)\end{array}$ & 0 & 3 & 4 & 298 & $0 \%$ \\
\hline $\begin{array}{l}\text { Diagnostics } \\
\text { Assessment } \\
\text { Programme (2011- } \\
\text { 2018) }\end{array}$ & 31 & 0 & 0 & 0 & $100 \%$ \\
\hline $\begin{array}{l}\text { Medical Technology } \\
\text { Assessment } \\
\text { Programme (2011- } \\
\text { 2018) }\end{array}$ & 8 & 27 & 0 & 0 & $23 \%$ \\
\hline $\begin{array}{l}\text { Highly Specialised } \\
\text { Technology Guidance } \\
\text { (2015-2018) }\end{array}$ & 0 & 0 & 0 & 7 & $0 \%$ \\
\hline
\end{tabular}

*Liquid-based cytology for cervical screening (TA69, replacing TA5).

Note: Data on guidance documents were downloaded from official NICE guidance search (NICE 2018), with a cut-off point in June 2018, and were classified by ResearcherA into technology categories. For quality check purposes, classification of technologies in the Technology Appraisal programme was cross-checked with NICE's own classification obtained from: https://www.nice.org.uk/about/what-we-do/our-programmes/niceguidance/nice-technology-appraisal-guidance/data/appraisal-recommendations (no similar data is available for NICE's other programmes). Unlike the Technology Appraisal data, official NICE guidance search results do not include technology guidance that has been replaced and is no longer valid; for consistency purposes, we have therefore limited our overview to valid guidance documents only for all programmes.

Despite its broad remit, NICE's technology evaluations have predominantly focused on pharmaceuticals. Until the creation of programmes dedicated specifically to diagnostics and medical devices we describe later in this paper, NICE's flagship Technology Appraisal programme had evaluated only one diagnostic technology, and pharmaceuticals continue to make up the majority of NICE's recommendations until today (see Table 1). Diagnostic innovation in the UK, as elsewhere, has largely been regulated informally by professional norms away from state scrutiny (Hopkins 2006). Yet today, the UK is considered one of the 
frontrunners in the evaluation of diagnostic technologies (Garfield et al. 2016). How did this come about and what impact has it had on the clinician-led hidden innovation system?

We examine the drivers of diagnostic reform in the UK and the way these drivers helped to shape the institutions that emerged. We argue that diagnostic reform in the UK has been a process of fragmented regulatory expansion - the traditional hidden innovation system, largely shielded from external controls, persists alongside new governance mechanisms that function as regulatory niches: discrete spaces within the overarching sociotechnical regime of clinical pathology. In the UK, there are three such niches: the UK National Screening Committee (NSC), NICE’s Diagnostics Assessment Programme (DAP), and the UK Genetic Testing Network (UKGTN).

Our paper contributes to intersecting strands of research. Scholarship on the regulation of biomedicine is dominated by work on therapeutics - we focus on diagnostics. To theorists of regulatory governance, we offer the concept of the regulatory niche, a new approach to regime analysis that links organisational structures to regulatory epistemologies. Our national case study contributes to scholarship on the British regulatory state, situating diagnostic reform in the broader political context of the contest for power between the state and the medical professions. We argue that regulatory niches differ in their effects and each emerges from a unique confluence of drivers, both mediated by and in turn mediating sectoral politics, which in the UK case include not only the regulatory state and the healthcare professions but influential non-governmental organisations (NGOs). Finally, we offer a new perspective on the concept of the niche, which has been adopted by a number of science and technology (STS) scholars to explain the emergence of new sociotechnical domains. 


\section{Theorising regulatory expansion}

A variety of macro-level models are used to explain the expansion of regulatory governance in recent decades. It is part of the emergence of a "risk society" (Beck 1992); it signals a change in the role of the state, broadly construed as a shift from rowing to steering, or from government to governance (Majone 1997); or, it exemplifies a new form of regulatory capitalism, defined by a dynamic of "more regulation, more capitalism" (Braithwaite, 2008). These broad frameworks are, however, inadequate to explain the scale, pace and form of institutional change in specific locales and sectors. Focusing on the domestic politics of UK healthcare, we analyse the confluence of multiple dynamics: high-profile scandals; technological change; institutional isomorphism; marketisation and transnational policy transfer. These factors interact to drive regulatory expansion. This section reviews them in more detail, presents their potential application to our case study, and elaborates on our concept of regulatory niches.

\subsection{Drivers of diagnostic reform}

Regulatory reformers thrive on scandal and tragedy, they store "regulatory development projects in their back drawer until the right disaster comes along" (Braithwaite 2008, 32). The emergence of the modern pharmaceutical regulatory regime following the Thalidomide scandal exemplifies this model and similar scandals may offer windows of opportunity for regulatory expansion in the diagnostics sector. For instance, the US Congress gave FDA powers to regulate medical devices (including diagnostics) after the Dalkon Shield scandal (Zuckerman, Brown, and Nissen 2011).

Technological change explanations often focus on how emergent technologies challenge existing regulatory systems. Regulators may respond to emergent biotechnologies by creating 
new governance frameworks or adapting existing ones (Faulkner 2012a, 2009).

Molecularisation, defined here as the growth in the use of genomic diagnostics, in particular, has prompted FDA policy changes in the USA, (Hogarth 2012) and heightened scrutiny by HTA agencies (Trosman, Van Bebber, and Phillips 2011). In this paper, we link technological innovation to broader sociotechnical changes, which we relate to another driver of regulatory expansion: marketisation.

Marketisation, the creation of new markets, often through the transfer from the public to the private sector of economic activities and assets, may require the creation of new regulatory frameworks. Such developments exemplify how state regulation is a precondition of, rather than an impediment to, market exchange (Harcourt 2011). We therefore look for evidence that the NHS hidden innovation system might be under pressure, not only from diagnostic reformers or the central state, but from the diagnostics industry.

In some cases, this commercial pressure may be interlinked with technological change. As Hancher and Moran $(1989,295)$ have argued, regulatory arenas are disrupted by two forms of economic innovation: "newly invented products or marketing form.". The rise of the molecular diagnostics sector is associated with a number of interlinked trends: a shift from the public-sector led hidden innovation system, as firms takes a more central role in the development of new technologies; a move from the industry's traditional high-volume, lowmargin business model towards premium pricing with patent-protected tests costing several thousand dollars; and, the adoption of aggressive marketing strategies, such as physician detailing and consumer advertising (Hogarth, Hopkins, and Rodriguez 2012). Resourceconstrained healthcare systems may respond by tightening regulatory controls. Diagnostic reform thus may be shaped by marketisation and efforts by the state both to enable and to constrain the activities of industry. 
Institutional isomorphism, where organisations within a field become more homogenous by emulating influential practices (DiMaggio and Powell 1983), may help to explain policy transfer within a sector, for instance when new technologies challenge established sectoral divisions. A key issue in relation to emergent biotechnologies "is the extent to which different fields 'require' different regimes and the extent to which existing regimes may be extended in acts of commensuration" (Faulkner 2012b, 360). This debate is notable for example in the field of HTA of "non-drug technologies" (EUnetHTA 2017). Although originally developed to assess diagnostics (Banta and Perry 1997), the application of HTA became much more prevalent in pharmaceuticals, and, paradoxically, pharmaceutical HTA is now seen as a model for coverage evaluation of diagnostics (Garfield et al. 2016). We therefore look for evidence of regulatory models crossing sectoral boundaries, for instance from pharmaceuticals to diagnostics.

International transfer of ideas and policies is a distinct form of institutional isomorphism and another possible explanation for diagnostic reform. Policy solutions, and ways of framing problems, travel across countries, a process exemplified in healthcare by EBM (Mykhalovskiy and Weir 2004) and HTA (Löblová 2016). We therefore look for evidence of transnational networks of experts exchanging ideas and practices relevant to diagnostics.

\subsection{UK regulatory politics}

These potential drivers of regulatory expansion operate within the context of domestic politics. The UK is considered a paradigm of regulatory capitalism; many scholars see it as "offering the leading case of sustained regulatory innovation (and even hyper innovation)" (Scott 2006, 119). In Moran's account, the regulatory state that emerged in late twentiethcentury Britain aims at achieving "synoptic legibility": it creates reporting and surveillance systems; exerts pressure to "make explicit what had hitherto been tacit" by standardizing and codifying knowledge and practices; and creates new institutions, notably specialised 
independent regulatory bodies (Moran 2003, 153-54). This new mode of governance emerged as a challenge to the established mechanisms of "club government" (Moran 2003, 147): an elite system of power, largely unconstrained by formal mechanisms of democratic accountability, which was "light-touch, peer-controlled, of insiders by insiders".

The advent of the regulatory state within the healthcare system threatened clinical autonomy (Moran 1995, 2003; Salter 2004). The "new politics of medicine" (Salter 2004) are defined by a tug contest between healthcare professionals and the "centralising impulse" of the British regulatory state (Moran 2003). However, Moran argues that the success of the regulatory state's centralising impulse was always contingent and resistance was often successful. Salter $(2004,199)$ similarly concludes that British physicians successfully resisted state managerialism, since regulators and politicians depend on the cooperation of clinicians - this is the "reality of knowledge control, the basis of medical power" (Salter 2004, 199). Knowledge politics are at the heart of our analysis; bodies such as NICE enable the regulatory state to limit clinical autonomy by co-opting EBM and HTA as alternate forms of expertise (Harrison and Dowswell 2002). Such expertise might be considered generic, but it is given unique institutional character in each of our three regulatory niches by the specific evaluation frameworks they have adopted. Niches can in large part be distinguished by the particular features of these new mechanisms of knowledge production.

\subsection{Regulatory niches}

Contemporary regulatory theory has questioned the traditional model of regulation as a hierarchical relationship between regulator and regulatee. Concepts such as polycentric regulation (Black 2008) theorise regulatory regimes as diffuse networks in which various actors perform regulatory functions. However, this model has a limitation: it assumes a unitary object of regulatory attention. Regulatory regimes are designed to address a problem which the regime "both defines and is defined by" (Black 2008, 140). But if there is more 
than one regulatory problem, then we may need a more fine-grained approach to regulatory regime analysis, hence our concept of regulatory niches as discrete spaces within an overarching regime, and our model of diagnostic reform as fragmented regulatory expansion.

Our framework departs somewhat from the niche concept as it is commonly used in STS. Theorists of socio-technical transitions (Schot and Geels 2007) describe regulatory niches as a subset of innovation niches - "protected socio-technical spaces" in which emergent technologies can be "nurtured, tested and further developed" (Gardner and Webster 2016, 91). Actors construct niches when they perceive the dominant sociotechnical regime to be detrimental to development of emergent technologies (Gardner and Webster 2016). We agree niches are defined by norms and practices that differ from those of the prevailing regime, but we question the techno-centric premise that a desire to nurture radical or disruptive innovation is necessarily the main driver of niche emergence and, by extension, the determining characteristic of the new regulatory institutions' practices.

\section{Methods}

This paper relies on a mixed-method approach. In July 2018 we created a dataset of diagnostics evaluations: guidance from NICE's Medical Technology Evaluation Programme (MTEP), Technology Appraisal Programme, Highly Specialised Technologies Programme, and DAP (NICE 2018), recommendations of the NSC (phe.org.uk 2018) and UKGTN (UK Genetic Testing Network 2017). Analysis using Excel generated descriptive statistics. Our primary approach was qualitative: manual qualitative content analysis of policy documents and semi-structured interviews with experts knowledgeable about diagnostic innovation in the NHS, including members of the three niches (see table 2). Our interviewees did not 
identify patient organisation representatives as relevant for the development of the three niches.

We employed purposive sampling and identified potential interviewees in publicly available documents, supplementing with snowball sampling. We invited 63 individuals to participate and 34 interviews were conducted in 2018/2019. Interviews were analysed using manual qualitative content analysis based on inductive and deductive codes (Schreier 2014). Elite/expert interviews with a historical focus carry potential risks of omission, misrepresentation, deception or recall bias (Morris 2009). Therefore, information was systematically triangulated with data from other interviews and written documents. Our analytic approach draws on the tradition of case study and policy analysis, dictating data comprehensiveness, context-specificity and a critical interpretive stance to generate a holistic portrait of a policy/organization (Yin, 2009), to provide data generalizable to theoretical propositions (Eisenhardt, 1989).

Our research received ethical approval from the Sociology Department, University XXX. Interviewees received a consent form and information about our research. All interviewees gave consent. All interviews were anonymised.

Table 2. Interviewee affiliations

\begin{tabular}{|l|l|l|l|}
\hline $\begin{array}{l}\text { Interviewee category (main } \\
\text { affiliation) }\end{array}$ & $\begin{array}{l}\text { Number of } \\
\text { interviewees }\end{array}$ & $\begin{array}{l}\text { Refusals, redirects } \\
\text { and non-responses }\end{array}$ & Response rate \\
\hline $\begin{array}{l}\text { Civil service/public } \\
\text { administration }\end{array}$ & 9 & 5 & $64 \%$ \\
\hline Academia/research & 7 & 8 & $47 \%$ \\
\hline Clinician-researchers & 5 & 2 & $71 \%$ \\
\hline $\begin{array}{l}\text { Diagnostics/biomedical } \\
\text { industry }\end{array}$ & 3 & 2 & $60 \%$ \\
\hline
\end{tabular}




\begin{tabular}{|l|l|l|l|}
\hline NGOs & 3 & 3 & $50 \%$ \\
\hline Payers & 3 & 6 & $30 \%$ \\
\hline Regulatory bodies/niches & 4 & 3 & $51 \%$ \\
\hline Total & $\mathbf{3 4}$ & $\mathbf{2 9}$ & $54 \%$ \\
\hline
\end{tabular}

\section{Findings}

\subsection{The emergence of evaluation frameworks for diagnostics}

Before we address our national case study, we describe the development and international diffusion of the evaluative frameworks that give each niche its distinctive character: HTA, the Wilson and Jungner guidelines, and the ACCE framework.

HTA emerged in the USA in the mid-1970s, focusing on safety, clinical effectiveness and cost-effectiveness. The evaluative framework encompasses ethical and social issues, but these are rarely addressed (Velasco Garrido et al. 2008). Of our three frameworks HTA has the broadest scope - it is applied to all kinds of clinical interventions. Our remaining two evaluative frameworks were developed to address specific types of diagnostic testing.

In 1968 the World Health Organisation (WHO) published a new model for the evaluation of screening (Wilson and Jungner 1968). This guideline established the importance of a programmatic approach to screening and the need to assess the harms and benefits of new screening programmes as complex healthcare interventions. Evaluation encompassed not only the performance of the screening test, but the subsequent treatment pathways and the nature of the disease (which should be an important public health problem).

The ACCE framework for evaluation of genetic tests was developed by the Foundation for Blood Research and the Office for Public Health Genomics (OPHG) at the US Centers for Disease Control (Haddow and Palomaki 2004), and encompasses four dimensions: Analytic 
validity, Clinical validity, Clinical utility and Ethical, legal and social issues. ACCE had its origins in policy deliberations about genetic testing by expert-led committees in the US; its distinctive emphasis on ethical issues and its framing of the concept of clinical utility reflected the belief that genetic tests were an exceptional technology that posed unique risks (Sturdy, this issue).

These three frameworks differ in scope and nomenclature but they were all developed, at least in part, as responses to technological change: the WHO guidelines were a response to the growth in screening, fuelled by a trend for 'multiphasic' screening using automated diagnostic platforms that tested for multiple diseases simultaneously (Wilson and Jungner 1968); HTA emerged from concerns about the uncontrolled diffusion of CT scanners (Banta and Perry 1997); and the ACCE framework was a response to the growth in genetic testing (Haddow and Palomaki 2004).

These three frameworks have diffused around the world. A 2015 WHO survey found that $80 \%$ of respondents reported an HTA process to inform decision-making in their country, and two-thirds of countries had a state-commissioned organisation conducting HTA (Hill et al. 2015). Advisory committees responsible for assessing screening interventions were established in Canada (1976) and USA (1984), and a 2014 survey found 13 similar bodies in Europe and Asia Pacific (Seedat et al. 2014). All have adopted/adapted the Wilson and Jungner guideline, which has proven "remarkably enduring" (Dobrow et al. 2018). A 2018 survey of 29 mechanisms for evaluating genetic tests found that the majority drew on the ACCE framework (Pitini et al. 2018).

Transnational networks of expertise have played an important role in the diffusion of these frameworks. HTA practitioners are linked through bodies such as INAHTA. The ACCE framework is the product of public health genomics, a multidisciplinary field comprising 
clinicians, epidemiologists, lawyers and bioethicists. There are strong links between the US OPHG and the UK Public Health Genomics Foundation (PHGF), and international networks such as GRAPH-Int. The Wilson and Jungner guidelines were developed under the auspices of the $\mathrm{WHO}$, and the two co-authors first met at international meetings on screening policy in the early 1960s (Jungner et al. 2017). Many advocates of a new approach to screening evaluation had a broader agenda. Leading figures in what became the EBM movement, including David Sackett in Canada and Archie Cochrane in Britain, published on screening in the late 1960s/70s and became members of screening governance bodies. David Sackett was a founding member of the Canadian Task Force and a contributor to its first major publication - an evidence review that evaluated the effectiveness of screening for 78 different medical conditions. This paper was a significant landmark, marking the first use of the evidence hierarchy that is a defining feature of EBM (Hill, Frappier-Davignon, and Morrison 1979; Canadian Task Force on Preventive Health Care n.d.). Sackett subsequently collaborated with Muir Gray, another influential EBM pioneer, who helped establish the Cochrane Collaboration (the leading international EBM organisation), and subsequently became the founding director of the UK National Screening Committee.

Our three evaluation frameworks were driven in part by technological change and diffused through emergent transnational networks of expertise. However, evidence of transnational diffusion cannot answer questions about the scale, pace, nature and timing of diagnostic reform in specific countries. To address these questions we turn to our national case study, examining the emergence, structure and impact of our three niches. 


\subsection{National Screening Committee}

Although first proposed in 1968, a national system for the evaluation of screening programmes was not established in the UK until 1996. Nevertheless, the UK played an important role in the development of screening governance, not least through Maxwell Wilson, co-author of the WHO 1968 guidelines. A Senior Medical Officer at the British Ministry of Health, Wilson became involved with WHO after being commissioned to investigate the growth of screening by the UK's Chief Medical Officer.

Concurrent with work on the WHO guidelines, Wilson participated in a domestic initiative a report on the evidence for screening for a variety of conditions sponsored by the Nuffield Provincial Hospitals Trust. The 1968 report recommended a more systematic approach to screening evaluation but suggested that "in Britain there would be objections to a request for statutory powers to enable central government departments to exercise control over local services" (McKeown 1968, 172). Given that the Trust represented provincial hospitals, this argument perhaps demonstrates Hancher and Moran's $(1989,296)$ observation that all regulatory actors have "complex arrays of interests". The solution proposed was to rely on the informal powers characteristic of club government - a national committee providing expert guidance "could have a profound effect on both the investigation and practice of screening, deriving its influence from the personal standing of its members rather than from statutory powers" (McKeown 1968, 172).

The government immediately established the Joint Standing Subcommittee on Screening in Medical Care, charged with reviewing the evidence for screening interventions and advising on new programmes. The committee succeeded in preventing adoption of universal health checks but its subsequent impact was limited, suggesting that it proved an ineffectual form of club government: 
"It was the kind of committee that existed in those days - distinguished men sitting around a table deciding what they should tell people to do in a paternalistic way" (UK 33, civil servant).

The body ceased to meet in 1980 and UK screening practice "grew haphazardly with little link to evidence" - by the mid-1990s there were a very small number of national screening programmes, but a proliferation of local initiatives had created a patchwork of over 300 "unevaluated and unregulated screening practices within the NHS" (Raffle and Gray 2007, 18-19).

Even national programmes were delivered locally, creating major variations in practice and quality. Cervical screening began nationally in 1965, but only in 1988 was a degree of centralisation established with a computerised national call-and-recall system, quality assurance measures and clearer guidelines on the target population. Despite improvements, problems continued during the 1990s, and media reports revealed a series of failures in local delivery (Albrow et al. 2012). Further stimulus for reform came from concerns about the commercial promotion of new cervical screening technologies such as automated slide readers and molecular tests for human papilloma virus (HPV) (UK 33, civil servant). The creation of a national governance framework was announced in 1994 by the Chief Medical Officer, Sir Kenneth Calman, in a speech linking the cervical screening scandals with the need for systematic evidence review:

\footnotetext{
"We have seen in the past screening tests creeping into the health service in a piecemeal and uncoordinated fashion and without quality assurance. Cervical screening has been part of the NHS since the 1960s but was implemented in an ad hoc fashion without the basis of solid research evidence, leading to variations in local practice" (BMJ 1994, 357).
}

Similar to the Thalidomide tragedy of the 1960s, public scandal opened a policy window and the UK National Screening Committee was established in 1996. Its current membership comprises health professionals, public health experts, ethicists and health economists, 
patient/public representatives, and representatives of the UK's devolved nations ("UK National Screening Committee - GOV.UK" n.d.). The NSC reviews current and potential screening programmes and consults widely on major decisions ("UK NSC Evidence Review Process - GOV.UK” n.d.). Individual diagnostic technologies play a key but limited part in NSC evaluations, in parallel to implementation and treatment. Like its Canadian/US counterparts, its decision-making criteria draw on the 1968 Wilson and Jungner framework, exemplifying how international policy transfer shapes domestic regulatory expansion.

The NSC is a powerful gatekeeper with high standards: out of the 113 screening programmes it has considered, it implemented 30, a $73 \%$ rejection rate (Table 3). As one of its members put it,

"the most useful thing that the UK National Screening Committee can do is to stop screening from starting. [The NSC] is a gatekeeper and [...] sometimes we're called 'the committee that says no' " (UK 14, researcher).

Table 3. Recommendation rates of the three regulatory niches

\begin{tabular}{|l|r|r|r|}
\hline & Technologies assessed & Positive recommendations & Recommendation \\
\hline NICE DAP & 94 & 47 & rate \\
\hline NICE MTEP* & 8 & 7 & $80 \%$ \\
\hline UK NSC & 113 & 30 & $27 \%$ \\
\hline UKGTN** & 557 & 453 & $81 \%$ \\
\hline * Diagnostics only & & & \\
\hline ** 2017 data & & &
\end{tabular}

Note: MTEP evaluations were classified into technology categories (devices vs. diagnostics). UK NSC provides clear yes/no decisions, but DAP and MTEP do not, so DAP/MTEP guidance were classified into binary 
recommendations by [ResearcherA]. Recommendations such as "for research use" were considered negative decisions. Given that DAP often assesses multiple technologies in a single guidance, we counted the total technologies assessed/recommended. UKGTN does not provide details on unapproved Gene Dossiers but published the number of its positive evaluations and total dossiers in a 2017 report.

Source: NICE (NICE 2018); UK NSC (phe.org.uk 2018); UKGTN (UK Genetic Testing Network 2017).

Adoption of new technologies, including molecular tests, has required substantial evidence. For instance, the trial to evaluate HPV testing in cervical screening ran for nine years from 2001, and a final decision to implement HPV testing was not made until 2016. Evaluation encompassed not only test performance, but clinical and cost-effectiveness and psycho-social impact. Our NSC interviewee expressed scepticism about much of the hype around the new generation of molecular screening technologies.

“[test developers] will have a test which is very good at picking up disease but they often come at far too early a stage [of test development]. [... They] don't have the data. [...] We really need populationbased studies..." (UK 14).

The committee's formal remit is management of population screening programmes. However, in practice the NSC acts as a brake on extensions in opportunistic (ad hoc) screening, because the dynamic of centralised quality control and technology assessment has established programmatic screening as the de facto standard in the NHS. The issue illustrates how the power of a gatekeeping body may extend beyond its formal remit, suggesting that the boundaries of a regulatory niche may be an important site of contestation.

\subsection{UK Genetic Testing Network}

The NSC established a model of centralisation that combined evidence review with quality control of service delivery. This was replicated in our second niche: UKGTN. However, in this case the primary driver was technological change, not public scandal, and the network of 
transnational expertise was public health genomics, not EBM. Mirroring Maxwell's role in screening governance, a UK figure again played a pioneering role. In 1997 Ron Zimmern was appointed founding Director of the Public Health Genetics Unit (subsequently renamed Public Health Genomics Foundation, PHGF hereafter), rapidly establishing influence in UK genomics policy, and helping to draft the government's 2003 Genetics White Paper (Secretary of State for Health 2003). As well as support for UKGTN, this document promised additional funding for clinical genetics services and established various schemes to broaden the impact of genetics across the NHS. NHS-focused initiatives were linked to the government's innovation strategy, the chapter on R\&D emphasised the importance of working with industry and committed $£ 246$ million over five years for "post-genomics and proteomics research" and $£ 25$ million for a programme focused on the biotechnology industry (Secretary of State for Health 2003, 60).

UKGTN was established in 2002, ahead of the White Paper. A voluntary network of accredited laboratories providing genetic tests for rare diseases, UKGTN's remit addressed multiple dimensions of service quality, including laboratory accreditation. The White Paper extended the role of UKGTN, establishing it as a forum for the centralised evaluation of new tests. UKGTN established a directory of tests available across the NHS and new tests were added only after evaluation through the "gene dossier" process, an evidence review mechanism based on the ACCE framework. The PHGF had argued for some time that such a mechanism was required given the rapid growth of genetic testing in the 1990s, and the NGO now helped to implement the new evaluation process (UK 26; 27). Ron Zimmern sat on the UKGTN steering group, and Mark Kroese, a public health consultant attached to PHGF, was on the gene dossier working group (Genetic Test Evaluation Group - UKGTN n.d.). The UK thus became the first country to institutionalise use of the ACCE framework developed in the USA by OPHG, PHGF's US counterpart. International policy diffusion was facilitated by 
strong transatlantic ties - Kroese spent time at OPHG during his training and the two groups collaborated on multiple projects.

The clinical genetics community showed some resistance to the gene dossier process:

“... the majority were dead against it and it took a number of years before they themselves understood the value" (UK 27, NGO).

“... people are resistant to change but I think there was a recognition of the need for standards [...] and essentially they did sort of go along with it." (UK 26, researcher).

However, the majority of the review committee were members of the clinical genetics community, and although the review process created a formal evaluation framework, in practice the evidentiary threshold accommodated nearly all submissions. The gene dossier process was, in the words of two interviewees, "quick and dirty" (UK 26; 27), a pragmatic accommodation to the reality that gathering clinical evidence on tests for rare genetic diseases is difficult. Thus, in contrast to the NSC, UKGTN said yes far more often than it said no - by 2017 the gene dossier recommended 453 out of 557 tests, an acceptance rate of just over $80 \%$ (Table 3). However, a simple tally of yes/no decisions does not fully capture the impact of UKGTN, which also developed de facto clinical guidelines that successfully restricted testing for conditions such as Fragile-X syndrome where there had been concerns about overuse (UK 26; 27). Nevertheless, the permissive gene dossier process supported the continued growth of genetic testing, conforming to the STS model of the niche as safe haven for emergent biotechnologies. NICE DAP, our final regulatory niche was also, in part, impelled by concerns about the future of genomics in the UK, but, like the NSC, it is technology-agnostic and it provides evidence of another dynamic: institutional isomorphism. 


\subsection{NICE Diagnostics Assessment Programme}

Having helped establish the UKGTN framework for evaluating rare disease genetic tests, PHGF broadened its focus, promoting policy discussion about how the NHS might extend the UKGTN model to other areas of pathology. At this time PHGF was functioning as the core of the Cambridge Genetics Knowledge Park (CGKP), one of five such bodies established to support the translation of genomics into medical practice. In November 2005, the Oxford GKP and the National Translational Cancer Research Network co-convened a national meeting to discuss the challenges around the introduction of molecular diagnostic tests into the NHS. Much of the discussion focused on cancer, the only clinical area beyond clinical genetics where molecular diagnostics were gaining significant traction. Two of the main speakers at the event were Ron Zimmern and David Barnett, Chair of the NICE Appraisals Committee. The meeting recommended a bifurcated approach to the evaluation of new molecular diagnostics within the NHS - tests that target a "large population with a common disease type [and] require large-scale introduction" should go through NICE, but genetic tests targeting rare diseases could be introduced using a combination of "a bottom-up professionalled, multi-disciplinary approach, and national protocols to ensure a standard approach" (OxfordGKP and NTRAC 2005) .

The following year, RCPath entered the debate with the publication of a report calling for a new framework for diagnostic innovation within the NHS (Royal College of Pathologists 2006). The current patchwork of test evaluation programmes failed to provide a comprehensive framework, and the established informal process of diagnostic development was no longer tenable given the rapid pace of innovation in genomics. The report suggested that NICE might be the most feasible option as the body to address the problem, but it suggested that the ideal solution would be a NICE-like body focused solely on diagnostic tests. The report concluded that a meeting of all stakeholders should be convened to advance 
discussion. It would take over a year to achieve this aim, but 2008 saw an intensification of lobbying efforts to extend the UKGTN model, the formation of new alliances to further this goal, and a parliamentary enquiry that brought the issue into the domain of high politics.

In January 2008, RCPath and PHGF co-convened a "diagnostic summit". The subsequent report echoed RCPath's 2006 call for a new organisation charged with evaluation of diagnostic tests, and cited UKGTN as a model, but it also suggested that responsibility might be vested with professional bodies (Furness et al. 2008). NICE assessments were recognised as "the gold standard", but the NICE process was rejected as "too slow" for the anticipated workload (Furness et al. 2008, 16). In a clear instance of institutional isomorphism, Peter Furness, President of RCPath, drew on an example from pharmaceuticals policy, invoking the British National Formulary (which provides detailed information on all drugs approved for use in the NHS), as an example that could be extended to diagnostics (Furness et al. 2008, 7). The concluding recommendations of the report tied the test formulary/database proposal to establishment of a new evaluation body for diagnostics and set out evaluation criteria based on the ACCE framework. The UKGTN gene dossier process thus became a model for comprehensive evaluation of diagnostics in the NHS, and RCPath and PHGF promoted diagnostic reform in a framework which facilitated professional self-regulation. This development confirms Salter's (2004) thesis that clinicians seek to retain control by co-opting or pre-empting the regulatory state, but in this case an influential NGO is playing a supporting role.

The formulary proposal reappeared in 2008 in a report on direct-to-consumer screening which featured both Furness and Zimmern (Sense About Science 2008), and then in RCPath's written evidence to the 2008 Parliamentary Inquiry on Genomic Medicine, conducted by the House of Lords Select Committee on Science and Technology (Royal College of Pathologists 2008). Despite the Inquiry's focus on genomics, PHGF and 
RCPath used the forum to lobby for a new evaluation body with a comprehensive remit across all pathology. The Committee resisted broadening the Inquiry's scope, restricting its recommendations to genomics, and calling for NICE to establish a comprehensive programme "for evaluating the validity, utility and cost-benefits of all new genomic tests for common diseases, including pharmacogenetic tests" (House of Lords Science and Technology Committee 2009, 31-32).

With its large staff, clear mandate, and emphasis on accountability through transparency and public consultation, NICE represented the typical "arm's length body" of the regulatory state, closer to the NSC than the model of professional control proposed by RCPath. The House of Lords' 2009 report noted that NICE was already developing a diagnostic evaluation programme, a development that was in large part a response to pressure from industry (UK 34; also Newland 2011). This industry lobbying can be seen as part of an effort to marketise NHS pathology and curtail its hidden innovation system. BIVDA, the UK trade body for IVD firms, has consistently lobbied the UK government for expansion of the NHS market, arguing that the UK spends less per capita on diagnostics than comparable countries because the NHS is reluctant to adopt new technologies and too reliant on in-house developed tests (Bufton 2001). BIVDA saw NICE as necessary to market expansion because of its gatekeeping function: "Its role in approving and recommending new technologies makes it an essential gateway to healthcare innovation." (BIVDA in House of Commons Health Committee 2013, II:NICE 53).

In 2009/2010, NICE established the Diagnostics Assessment Programme (DAP) and the Medical Technologies Evaluation Programme (MTEP) (Newland 2011). MTEP assesses single diagnostic technologies that are likely to be cost-saving/cost-neutral with comparable health outcomes to established technologies; most of its work is not on diagnostics (NICE 2018). DAP assesses "important" diagnostic technologies that may improve health outcomes 
but at additional cost, thus requiring "complex" evaluation of the cost-effectiveness of mutliple comparators (NICE 2011, 8).

DAP's and MTEP's committees involve various stakeholders, including pathologists and clinical biochemists; Mark Kroese, now Director of PHGF, is a longstanding member and current vice-chair of the Diagnostics Advisory Committee, which finalises NICE guidance decisions (NICE 2018). The evaluation framework for NICE DAP is set out in a methods document (NICE 2011) that was developed in 2010-11 by a specially convened group comprising academic HTA experts, industry representatives and staff from the Department of Health and NICE (Newland 2011). According to one interviewee, HTA experts were unhappy with the final outcome:

"There was not a consensus on what went into the document. NICE did not listen to the group and methodologists would not support it and one methodologist resigned from the group" (UK 34, academia).

There were conflicting priorities: methodologists hoped that DAP could address the lack of robust clinical evidence supporting new diagnostic tests; NICE staff focused on evaluation of cost-effectiveness "in order to maintain consistency across its programmes" (UK 34). However, responding to industry concerns over transferability of the pharmaceutical HTA model to diagnostics, NICE stated that DAP would accept lower-quality evidence than in its pharmaceutical-focused Technology Appraisal Programme (Crabb et al. 2012). This evidence gap would be addressed by use of modelling. The compromise was a source of contention: methodologists argued that "modelling would not work in same way as in pharmaceutical interventions" (UK 34). This process of attenuated isomorphism, delivered a framework that has been less permissive than UKGTN, but more accommodating than the NSC: of the 94 technologies DAP assessed, only 47 (50\%) received positive recommendations (Table 3). 
Although the genesis of NICE DAP can be partially attributed to the UK state's focus on genomics, DAP is technology-agnostic: only eight of the 31 assessments conducted thus far have evaluated molecular diagnostics (NICE 2018). Nevertheless, genomic diagnostics were identified by NICE as a key technological development due to their cost (Byron et al. 2014; Crabb et al. 2012), and one of DAP's first evidence reviews (DG10) evaluated the burgeoning field of multi-gene prognostic tests for breast cancer, involving DAP in a major policy dilemma: whether the NHS should pay for premium-priced diagnostics (the market leader Genomic Health charges \$4,175 for its Oncotype Dx test and the firm exemplifies the new model of diagnostics firms emulating pharmaceutical marketing strategies like physician detailing). Approval of Oncotype Dx came after a lengthy review process and NICE rejected a far cheaper in-house NHS test because it lacked sufficient evidence (National Institute for Clinical Excellence 2013). This outcome suggests that DAP is not a niche designed to nurture products of the NHS hidden innovation system.

\section{Discussion}

The process of diagnostic reform in the UK provides an example of fragmented regulatory expansion. We draw on our three niches, first, to compare the drivers of niche formation and their interaction with the new politics of medicine in the UK; second, to describe their impact on diagnostic innovation; and in conclusion, to reflect on the value of the niche as a contribution to regulatory theory.

\section{Diagnostic reform - what are the drivers of regulatory expansion?}

Given the fragmented nature of this process of regulatory expansion, it is unsurprising that there is no single explanation for the emergence of our three regulatory niches. They have all emerged as a consequence of interactions between transnational policy diffusion and domestic politics, but each niche is a product of a specific confluence of multiple interacting 
factors. UKGTN exemplifies the model of regulatory innovation as a response to the development of emergent biotechnologies; the NSC mostly closely fits the model of regulation as a response to scandal; DAP combines institutional isomorphism and marketisation.

Transnational policy transfer is clearly visible in the adoption of the WHO's 1968 screening principles by the NSC, emulating the pattern established in Canada and the USA; and again in UKGTN's adoption of the ACCE framework, which signalled the emergence of public health genomics as a transnational epistemic community. A similar, although more attenuated process, linked new national frameworks for screening governance to the international growth of the EBM movement.

Institutional isomorphism is observable in several instances of "regulatory pharmaceuticalisation" (Faulkner, 2012c). The clearest example is the creation of DAP, within NICE, an agency which had hitherto focused its technology evaluation activity predominantly on pharmaceuticals. When PHGF and RCPath cited the British National Formulary for pharmaceuticals as a model, isomorphic logic was again apparent. However, diagnostic reformers often temper the isomorphic impulse with arguments that emphasise how diagnostic tests/diagnostic innovation differ from pharmaceuticals/pharmaceutical innovation. Thus RCPath argued that the standard NICE assessment framework was too demanding and time-consuming for diagnostics. Similarly, the ACCE evaluation framework was, in effect, an alternative to standard HTA, developed in the belief that genetic tests were in some sense an exceptional form of medical technology.

Policy transfer, across borders or domains, can help explain the framing of problems in ways that help to construct niches - the idea that screening programmes or genetic tests are unique practices is co-produced through their distinctive evaluation frameworks - but how do 
problems become issues demanding political action; and how do evaluation frameworks become embedded in new organisational structures? Technological change was a key driver in the development of UKGTN, a body established specifically to address the rapid growth in genetic testing for rare diseases. Similarly, as was evident from the House of Lords (2009) report on genomic medicine, the creation of DAP was partly consequent on the broader growth in genomic testing beyond clinical genetics. Given the British state's commitment to genomics, it is a useful framing device to capture the attention of policymakers and to gain resources. That one of DAP's first evidence reviews addressed genomic tests for breast cancer prognosis suggests that molecularisation was salient (although not a key driver for DAP), but it also demonstrates that regulatory expansion is not defined solely by the need to manage technological innovation. The challenges presented by novel business models and marketing practices associated with new technologies heighten cost concerns. The NSC was established amidst disquiet about industry's promotion of new technologies, like molecular HPV tests, but the formation of DAP signalled a more ambivalent attitude towards marketisation: cost concerns were now balanced against the need to open the NHS to industry-led innovation.

Diagnostics have rarely been the topic of major public controversy, and scandal was a significant driver of regulatory reform in only one niche: the NSC. In screening, a series of public scandals about the quality of cervical screening led to increasing centralisation, first for programme quality assurance, and then to address regional variations in the range of screening activities. This example is consistent with the model of historical change in both Moran's account of the centralising impulse of the "hypermodernist" British regulatory state, and Salter's model of regulatory expansion in the healthcare system triggered by a series of public scandals. The policy solution of centralised control, and the Wilson and Jungner evaluative framework, were tentatively mooted but judged politically infeasible in 1968 , 
given the balance of power between the central state and regional health authorities. The cervical screening scandals in the 1980s and 1990s may have triggered centralisation, but it was the broader shifts in the UK's regulatory politics that created a climate conducive to change by the mid-1990s. The rise of the British regulatory state and its encroachments on the healthcare system were a necessary condition for niche formation, as was the diffusion of EBM, but diverse drivers such as scandal and marketisation were the proximate causes.

However, our account brings into question the binary model of UK healthcare politics as a contest for power between the state and the professions. Since 1997, PHGF has functioned as a non-governmental actor brokering between the state and the medical professions. Its influence underlines the importance of epistemic communities and NGOs in advancing policy solutions (Löblová 2018). The type of policy solutions advanced by PHGF may reflect its mediatory role. The gene dossier process exemplifies a pragmatic accommodation between the centralising regulatory state and the established "light-touch" club government model of professional governance.

\section{What has been the impact of regulatory expansion within each niche?}

Our three niches all encroach on clinical autonomy, restricting what tests are available and circumscribing their application in clinical practice. The impact of niches depends on their evidentiary standards, in particular their approaches to the evaluation of the clinical or cost effectiveness of diagnostic tests. The NSC has set a high bar: it routinely demands evidence from RCTs, and is the most likely of our three bodies to reject new technologies. The WHO evaluative framework it employs looks beyond diagnostic accuracy to clinical outcomes, reflecting the success of the 1968 guidelines in establishing the concept of the population screening programme as a complex health intervention. Large RCTs have thus become increasingly common in screening regulation since the 1970s. This presents a distinct contrast to the "quick and dirty" approach of UKGTN's gene dossier process, which rarely rejects 
submissions. The formal structures of UKGTN evidence review are challenged by the routine dearth of clinical evidence, thus bolstering the professional authority of the clinicians who play a leading role in the review process, and preserving the traditional hidden innovation system that has driven the growth of genetic testing. NICE sits between UKGTN and the NSC: clinical and cost effectiveness are central to their evaluation framework but NICE are less insistent on RCT data and more willing to use modelling when evidence on outcomes is lacking. However, NICE's leniency has limits and consequently its review process has favoured premium-priced diagnostics over (much cheaper) products of the NHS hidden innovation system. Anticipation of precisely this outcome may explain why RCPath favoured solutions other than enhanced powers for NICE.

Differences aside, all three regulatory niches perform gatekeeping functions, evaluating whether technologies within their remit can justify use of NHS resources. Individually, the three niches have set evidentiary expectations for each of their domains; together, they have exposed a few patches of the hidden innovation system to regulatory scrutiny.

\section{Conclusions}

Niches demonstrate that regulatory expansion can be fragmented, with diverse regulatory targets selected for different reasons, and a variety of rules and structures leading to uneven outcomes. We do not dismiss the established STS niche concept, but we propose that niche formation may only sometimes be associated with disruptive technologies. Instead, political change at the macro-level (the centralising impulse of the regulatory state), manifest at the sectoral level (the new politics of healthcare), may trigger reform at the sub-sectoral level (population screening) in response to a well-established technology (cervical cytology). Neither do regulatory niches simply function as "incubators" nurturing emergent technologies (Gardner and Webster 2016). On the contrary, they may be imbued with a culture of 
technological scepticism like DAP, restraining innovation by imposing regulatory processes and evaluative standards tailored to established technologies. Our explanatory framework thus suggests the limitations of an STS approach based on "following the science" at the expense of institutional context.

Niches are sites of contestation in which the breadth and depth of regulatory expansion is negotiated. Distinct institutional niches are shaped through accommodation and compromise between the centralising impulse of the regulatory state, and the boundaries and norms of the established clinical or commercial actors who are its regulatory targets. The enactment of different frameworks for evidence evaluation is central to this process. Here we return to Black's argument that regulatory regimes are designed to address a problem which the regime "both defines and is defined by" (Black 2008, 140). Evaluation frameworks are bespoke governance devices that frame a regulatory problem and define a regulatory niche.

If the boundaries of a niche are epistemological, as well as organisational, then what does this mean for subsequent regulatory expansion? A new regime could take multiple forms: organisational expansion, as a single body subsumes multiple independent niches; or epistemological expansion, with alignment to a common evaluation framework; or some combination of the two. Alternatively, niches may persist as discrete regulatory spaces without changing the overarching sociotechnical regime. Niche formation may use up the window of opportunity necessary for broader policy change, precluding more comprehensive regulatory proposals.

Future research might examine the boundaries of niches - how porous are they; how are they policed; when do they break down; where are the liminal spaces of overlap between niches, and how is this territory contested? Given our emphasis on the knowledge politics of evaluation frameworks as niche governance devices, we should investigate not only the 
organisational boundaries of regulatory bodies, but also their epistemological boundaries. Close attention to how evaluation frameworks are put into practice may reveal isomorphic trends even if organisational differentiation persists.

A second line of investigation would be to move from a single-country study to a comparative approach that could test the generalisability of our findings. We know that our three evaluative frameworks have travelled globally but what institutional form have they taken elsewhere? Comparative research could shed further light on the ways in which transnational networks of expertise are embedded within national institutions.

As a contribution to the scholarship on the regulation of diagnostics, we have offered some evidence of the broader significance of the topic. Diagnostic reform is not simply another manifestation of the broader regulatory expansion in healthcare; it is an important driver. The pioneers of EBM were also diagnostic reformers, and the creation of new mechanisms for the evaluation of diagnostic tests helped to establish the epistemological framework of EBM. The regulation of diagnostic tests is not a niche topic. 


\section{References}

Albrow, Rebecca, Henry Kitchener, and Mina Desai. 2012. "Cervical Screening in England: Past, Present, and Future.” Cancer Cytopathology 120 (2): 87-96.

Banta, David, and Seymour Perry. 1997. "A History of ISTAHC: A Personal Perspective.” Int. J. Technol. Assess. Health Care 13 (3): 454-57. https://doi.org/10.1017/S0266462300010692.

Beck, Ulrich. 1992. Risk Society: Towards a New Modernity. Sage.

Benoit, Cyril, and Philippe Gorry. 2017. "Health Technology Assessment: The Scientific Career of a Policy Concept.” Int. J. Technol. Assess. Health Care 1: 1-7. https://doi.org/10.1017/S0266462317000186.

Black, Julia. 2008. "Constructing and Contesting Legitimacy and Accountability in Polycentric Regulatory Regimes.” Regulation \& Governance, no. 2: 137-64. https://doi.org/10.2139/ssrn.1091783.

BMJ. 1994. "British Government Revamps Screening Policy.” British Medical Journal 308 (6925): 357-58.

Braithwaite, John. 2008. Regulatory Capitalism: How It Works, Ideas for Making It Work Better. Edward Elgar.

Byron, S., N. Crabb, E. George, M. Marlow, and A. Newland. 2014. "The Health Technology Assessment of Companion Diagnostics: Experience of NICE.” Clinical Cancer Research 20 (6): 1469-76. https://doi.org/10.1158/1078-0432.CCR-13-1955. 
Bufton, Andy. 2001. "Diagnostics - the Best Kept Secret in Healthcare." In Portcullis House, 13 November 2001. https://slideplayer.com/slide/5054331/.

Canadian Task Force on Preventive Healthcare. n.d. "History.” Accessed May 11, 2020. https://canadiantaskforce.ca/about/history/.

Harcourt, Bernard. 2011. The Illusion of Free Markets: Punishment and the Myth of Natural Order. Harvard University Press.

House of Commons Health Committee. 2013. "National Institute for Health and Clinical Excellence. Eighth Report of Session 2012-13 Volume II. Additional Written Evidence.” Vol. II.

Newland, Adrian. 2011. "NICE Diagnostics Assessment Programme.” Annals of The Royal College of Surgeons 93 (5): 412-13. https://doi.org/10.1308/rcsann.2011.93.5.412.

Crabb, Nick, Mirella Marlow, Hanan Bell, and Adrian Newland. 2012. "The NICE Diagnostics Assessment Programme.” Health Policy and Technology 1 (1): 5-7. https://doi.org/10.1016/j.hlpt.2012.01.005.

DiMaggio, Paul, and Walter Powell. 1983. “The Iron Cage Revisited : Institutional Isomorphism and Collective Rationality in Organizational Fields.” American Sociological Review 48 (2): 147-60.

Dobrow, Mark, Victoria Hagens, Roger Chafe, Terrence Sullivan, and Linda Rabeneck. 2018. "Consolidated Principles for Screening Based on a Systematic Review and Consensus Process.” CMAJ 190 (14): E422-29.

Eisenhardt, K. (1989). Building theories from case study research. Academy of Management Review, 14(4), 532-550.

EUnetHTA. 2017. “An Analysis of HTA and Reimbursement Procedures in EUnetHTA 
Partner Countries: Final Report | EUnetHTA.” http://eunethta.eu/outputs/analysis-htaand-reimbursement-procedures-eunethta-partner-countries-final-report.

Faulkner, Alex. 2009. "Regulatory Policy as Innovation: Constructing Rules of Engagement for a Technological Zone of Tissue Engineering in the EU." Research Policy 38 (4): 637-46. https://doi.org/10.1016/j.respol.2009.01.017.

. 2012a. "Resisting the Screening Imperative: Patienthood, Populations and Politics in Prostate Cancer Detection Technologies for the UK." Sociology of Health and Illness 34 (2): 221-33. https://doi.org/10.1111/j.1467-9566.2011.01385.x.

—. 2012b. "Steering Biomedicine: Regulatory Dynamics of Therapeutic Technologies in the EU and Beyond." Innovation 25 (4): 355-61. https://doi.org/10.1080/13511610.2012.730226.

—. 2012c. "Tissue Engineered Technologies: Regulatory Pharmaceuticalization in the EU.” Innovation 25 (4): 389-408. https://doi.org/10.1080/13511610.2012.723333.

Furness, Peter, Ron Zimmern, and Maria Adams. 2008. "Evaluation of Diagnostic Laboratory Tests and Complex Biomarkers.” In Summary of a Diagnostic Summit 14-15 January 2008, 1-27. papers2://publication/uuid/14747EC3-C747-4ABD-A009-1EB9A0663766.

Gardner, John, and Andrew Webster. 2016. "The Social Management of Biomedical Novelty: Facilitating Translation in Regenerative Medicine.” Social Science and Medicine 156: 90-97. https://doi.org/10.1016/j.socscimed.2016.03.025.

Garfield, Susan, Julie Polisena, Daryl Spinner, Anne Postulka, Christine Lu, Nick Poulios, Vladimir Zah, and Michael Longacre. 2016. "Health Technology Assessment for Molecular Diagnostics: Practices, Challenges, and Recommendations from the Medical Devices and Diagnostics Special Interest Group.” Value in Health 19 (5): 577-87. 
https://doi.org/10.1016/j.jval.2016.02.012.

“Genetic Test Evaluation Working Group - UKGTN.” n.d. Accessed September 13, 2018. https://ukgtn.nhs.uk/about-us/ukgtn-working-groups/genetic-test-evaluation-workinggroup/.

Haddow, James, and Glenn Palomaki. 2004. “ACCE: A Model Process for Evaluating Data on Genetic Tests.” In Human Genome Epidemiology: A Scientific Foundation for Using Genetic Information to Improve Health and Prevent Disease, edited by M Khoury, Little J, and W Burke, 217-33. Oxford University Press.

Hancher, Leigh, and Michael Moran. 1989. Capitalism, Culture, and Economic Regulation. Oxford University Press.

Harrison, Stephen, and George Dowswell. 2002. "Autonomy and Bureaucratic Accountability in Primary Care: What English GPs Say.” Sociology of Health and Illness 24 (2): 208-26. https://doi.org/10.1111/1467-9566.00291.

Hill, Susanne, Adriana Velazquez, and Alexandra Metherell. 2015. “2015 Global Survey on Health Technology Assessment by National Authorities." WHO. www.who.int\%0Awww.who.int/about/licens-ing/copyright_form/en/index.html.

Hill, N., Frappier-Davignon, L. and B. Morrison. 1979. The periodic health examination. Canadian Medical Association Journal, 121, pp.1193-1254

Hogarth, Stuart. 2012. "Regulatory Experiments and Transnational Networks: The Governance of Pharmacogenomics in Europe and the United States." Innovation 25 (4): 441-60. https://doi.org/10.1080/13511610.2012.726423.

Hogarth, Stuart, Michael Hopkins, and Victor Rodriguez. 2012. “A Molecular Monopoly? HPV Testing, the Pap Smear and the Molecularisation of Cervical Screening in USA.” 
Sociology of Health and Illness 34 (2): 234-50. https://doi.org/10.1111/j.14679566.2011.01411.x.

Hopkins, Michael. 2006. "The Hidden Research System: The Evolution of Cytogenetic Testing in the NHS." Science as Culture 15 (3): 253-76.

https://doi.org/10.1080/09505430600890701.

House of Lords Science and Technology Committee. 2009. “Genomic Medicine.” Hmso I (June).

Jungner, Lars, Ingmar Jungner, Martin Engvall, and Ulrika Döbeln. 2017. “Gunnar Jungner and the Principles and Practice of Screening." International Journal of Neonatal Screening 3 (3): 23.

Löblová, Olga. 2018. “Who’s Afraid of Institutionalizing Health Technology Assessment (HTA)? HTA in the Czech Republic." Health Economics, Policy and Law 13 (02): 13761. https://doi.org/10.1017/S174413311700024X.

McKeown, Thomas. 1968. Screening in Medical Care: Reviewing the Evidence. Oxford University Press.

Moran, Michael. 1995. "Three Faces of the Health Care State.” Journal of Health Politics, Policy and Law 20 (3): 767-81. http://www.ncbi.nlm.nih.gov/pubmed/8530775.

—. 2003. The British Regulatory State: High Modernism and Hyper-Innovation. Oxford University Press.

Morris, Zoë. 2009. “The Truth about Interviewing Elites.” Politics 29 (3): 209-17. https://doi.org/10.1111/j.1467-9256.2009.01357.x.

Mykhalovskiy, Eric, and Lorna Weir. 2004. "The Problem of Evidence-Based Medicine: Directions for Social Science.” Social Science and Medicine 59 (5): 1059-69. 
https://doi.org/10.1016/j.socscimed.2003.12.002.

NICE. 2013. "Gene Expression Profiling and Expanded Immunohistochemistry Tests for Guiding Adjuvant Chemotherapy Decisions in Early Breast Cancer Management:| Guidance | NICE.” NICE. https://www.nice.org.uk/guidance/dg10.

NICE. 2018. "Diagnostics Advisory Committee Members.” NICE. 2018. https://www.nice.org.uk/Get-Involved/Meetings-in-public/Diagnostics-AdvisoryCommittee/Members.

NICE. 2011. "Diagnostics Assessment Programme Manual,” no. December: 1-130. http://www.nice.org.uk/media/A0B/97/DAPManualFINAL.pdf.

NICE. 2018. “Guidance and Advice List | Guidance | NICE.” NICE. 2018. https://www.nice.org.uk/guidance/published.

OxfordGKP, and NTRAC. 2005. "Introducing Molecular Diagnostic Tests to the NHS: Mapping the Process."

phe.org.uk. 2018. “Current UK NSC Recommendations.” Phe.Org.Uk. 2018. https://legacyscreening.phe.org.uk/screening-recommendations.php.

Pitini, Erica, Corrado DeVito, Carolina Marzuillo, Elvira D’Andrea, Annalisa Rosso, Antonio Federici, and Paolo Villari. 2018. "How Is Genetic Testing Evaluated? A Systematic Review." European Journal of Human Genetics, 1.

Raffle, Angela, and J A Muir Gray. 2007. Screening: Evidence and Practice. Oxford University Press.

Royal College of Pathologists. 2006. "Evaluating and Introducing New Diagnostic Tests : The Need for a National Strategy." Report from the Short Life Working Group on the Evaluation and Introduction of New Tests. 2006. 
- 2008. "Statement from the Royal College of Pathologists In Response to the Call for Evidence on Genomic Medicine from the House of Lords Science and Technology SubCommittee."

Salter, B G. 2004. The New Politics of Medicine. Palgrave Macmillan.

Schot, Johan, and Frank W. Geels. 2007. "Niches in Evolutionary Theories of Technical Change." Journal of Evolutionary Economics 17 (5): 605-22. https://doi.org/10.1007/s00191-007-0057-5.

Schreier, Margrit. 2014. "Qualitative Content Analysis.” In The SAGE Handbook of Qualitative Data Analysis, edited by SAGE, 170-83. Thousand Oaks, CA.

Scott, Colin. 2006. "Between the Old and the New: Innovation in the Regulation of Internet Gambling.” In Regulatory Innovation: A Comparative Analysis, edited by Julia Black, Martin Lodge, and Mark Thatcher. Edward Elgar Publishing.

Secretary of State for Health. 2003. "Our Inheritence, Our Future: Realising the Potential of Genetics,” no. June: 1-99.

Seedat, F, L Cameron, S Stranges, N Kandala, H Burton, S Taylor-Phillips, and J Cooper. 2014. "International Comparisons of Screening Policy-Making: A Systematic Review."

Sense About Science. 2008. "Making Sense of Testing." Public Policy and Administration. https://doi.org/10.1177/095207670201700305.

Trosman, Julia, Stephanie Bebber, and Kathryn Phillips. 2011. "Health Technology Assessment and Private Payers' Coverage of Personalized Medicine.” Journal of Oncology Practice 7 (3S): 18s-24s. https://doi.org/10.1200/JOP.2011.000300.

UK Genetic Testing Network. 2017. "Promoting Gene Testing Together," no. March. 
"UK National Screening Committee - GOV.UK.” n.d. Accessed August 16, 2018. https://www.gov.uk/government/groups/uk-national-screening-committee-uk-nsc.

“UK NSC Evidence Review Process - GOV.UK.” n.d. Accessed August 17, 2018. https://www.gov.uk/government/publications/uk-nsc-evidence-review-process.

Velasco Garrido, Marcial, Finn Kristensen, Camilla Nielsen, and Reinhard Busse. 2008. HEALTH TECHNOLOGY POLICY-MAKING IN EUROPE: Current Status, Challenges and Potential. Copenhagen: World Health Organization, on behalf of the European Observatory on Health Systems and Policies.

Wilson, J, and G. Jungner. 1968. "Principles and Practice of Screening for Disease.” Public Health Papers 123 (3): 349. https://doi.org/10.1001/archinte.1969.00300130131020.

Yin, R. (2009). Case study research: Design and methods. SAGE Publications.

Zuckermann, DM, Brown, P, and S Nissen. 2011. "Medical Device Recalls and FDA Approval.” Archives of Internal Medicine 171(11) . doi:10.1001/archinternmed.2011.30 